\title{
Spatial Terrain Visualization for Counter Terrorism: A Case of North-Eastern Nigeria
}

\author{
${ }^{1}$ Muhammed S.O., ${ }^{1}$ Sadiya T.B., ${ }^{1}$ Eta J., ${ }^{1}$ Shaba H.A., Ibrahim A.T., ${ }^{1}$ Ozigis \\ S.M., Isa A.A., ${ }^{1}$ Sanusi U., ${ }^{1}$ Suleiman B.T. \\ ${ }^{I}$ National Space Research And Development Agency, Airport Rd., FCT, Abuja, Nigeria.
}

\begin{abstract}
Since the Boko-haram insurgency, in 2009 armed conflicts have become the order of the day in North-eastern Nigeria leading to a high number of civilian and sometimes military casualties. For a while the whereabouts and tactics of fighting back the insurgency eluded the Nigerian military mainly because the insurgent are locals with a good knowledge of the terrain. Thus, making it easier to make forays on motorized vehicles and still elude capture. For the military to be able to undertake offensive and rescue mission campaigns with fewer military casualty, knowledge of the terrain to which personnel are being deployed is very crucial. Thus, the ability of a field commander to carry out a successful spatial terrain analysis using up-to-date satellite/aerial images could mean the difference between life and death. In this research NigeriaSat-X images of North-eastern Nigeria were used to demarcate land use/land cover types using object-oriented classification. Ten classes were derived based on five of the ecological zones of Nigeria. The results of the classification together with a DEM, climate and vegetation characteristics, were used to design a cover/concealment index model which shows the ability of an area to offer cover/concealment to insurgent elements in the regions of conflict. The cover/concealment index ranges from 1 to 5 , with 1 being the lowest and 5 the highest cover/concealment ability. It is envisaged that the resultant concealment index model will be useful as a guide to locating insurgent strongholds, for rescue workers and military forces in the field.
\end{abstract}

Keywords: Insurgency, Terrorism, Boko-haram, geospatial analysis, GIS, remote sensing, North-east,

Nigeria.

\section{Introduction}

The insurgent group called Jama'atu Ahlis Sunna Lidda'awati wal-Jihad, which means "People Committed to the Propagation of the Prophet's Teachings" are commonly known as Boko-Haram, meaning "Western education is forbidden," was founded in 2002 by Mohammed Yusuf in opposition to Nigeria's democratic transition, nationalism and Western influence (Mauro, 2016). The group started as a peaceful protestant until 2009 when their leader was killed by the Nigeria police and Abubakar Shekau assume the seat of the slain leader (Noref Policy-Brief, 2014).

The Boko Haram insurgents have been the worst terrorist group operating since the inception of Nigeria as a sovereign nation because Conflicts between them and the Nigerian military have been for most of the time, inconclusive since on some occasions, the insurgents gain the upper hand over the military while on otheroccasions the military overpowers them (Ijiofor, 2015; Adebayo, 2015). Since Boko-haram violence started in 2009, thousands has lost their lives and millions have been rendered homeless.

Nonetheless, in any battle, a good knowledge of the terrain is crucial for any army to achieve success. Thus, the boko-haram insurgents are at an advantage due to the fact that most of their recruits (fighters) are from the immediate environment (Akinfala et al., 2014); which gives them a good knowledge of the terrain they are trying to have control over. Therefore, the forces with the better knowledge of the terrain will have a good chance of winning the battle due to the possibility of creating an element of surprise on the opposing forces while at the same time anticipating counter moves from them.

Therefore, terrain visualization was defined as the process through which a commander sees the terrain and understands its impact on the operation in which he is involved. This includes the impact on both friendly and enemy forces (Field Manual [FM] 34.230, 2000)

Since some of the Nigerian army and/or Joint task force (JTF) are not familiar with the battle field they might be deployed to, it is imperative that at least a hardcopy or softcopy of the terrain visualization be available for them to get familiarized with the environment of engagement. The more updated, available and detailed the maps are, the better the chance of reducing casualty on the battle field. There are several instances in which a battle was won by the side with fewer soldiers just because they have good battle field terrain strategies.

Firstly, in the battle between Persians and Athenians in 460BC, 6400 Persians were killed compared to 192 Athenians soldiers in the battle between Persians and Athenians in the Plains of Marathon; all because of the Persians lack of familiarity/knowledge of the battle field (Lane, 1986). 
Secondly, during the American civil war in 1863 at Gettysburg; Union Army had the upper hand against the Confederate Army because they control the hills and ridges (giving them a good observation and hiding places) south of the town (Civil War Trust, 2016).

Thirdly, The Germans were known to have started military geography after their defeat in World War 1, thus gaining greater advantage in World War II against their opponents (Lane, 1986). The Germans have done a lot of military geography publications in the 19th and early 20th centuries followed by the Americans, who engaged in military geography research especially in the area of Geology, Physical Geography and Military Mapping (Lane, 1986). Therefore, the significance of terrain analysis for battle field cannot be overemphasized. Terrain visualization is a component of battlefield information tool. It portrays and allows a detailed understanding of the background upon which enemy and friendly force's actions are displayed. Topography models provide the picture whereby the user can visualize the terrain. Terrain visualization includes the subordinate elements of data collection, database development, analysis, display, distribution, and database management. These elements include both new and changed tasks due to the new way of looking at the battlefield based on digital data (FM 3-34.230, 2000). As a result, this research took advantage of spatial terrain visualization for counter terrorism by the national forces and rescue workers in North-eastern Nigeria by taking into consideration the season for which the satellite image was captured. the research determine the general vegetation height, canopy and extent of coverage, terrain characteristics of the Sahel, Sudan, Northern and Southern guinea Savanna, the Derived

Savanna to produce a cover/concealment index for rescue workers, JTF and Nigerian Army in North-eastern Nigeria

\section{Study Area}

The study area is located in North-eastern Nigeria and it consists of three states namely Borno, Adamawa and Yobe bounded by coordinate of $10^{\circ} 0^{\prime} 0^{\prime \prime} \mathrm{E}$ to $140^{\circ} 0^{\prime} 0^{\prime \prime} \mathrm{E}$ and $6^{\circ} 0^{\prime} 0^{\prime \prime}$ to $140^{\circ} 00^{\prime \prime} \mathrm{N}$. The study area shares a border with Cameroon, Niger, Chad and has an elevation that varies spatially, with the lowest at $130 \mathrm{~m}$ Above Sea Level (ASL) while the highest elevation is known as the Adamawa Plateau or Vogel Peak bordering Cameroon is at least $1500 \mathrm{~m}$ ASL (Imaah, 2008). The study area is characterized by: Sahel Savanna (which is a semi-desert found in Yobe and Borno bordering Chad and Niger) to the extreme north then the Sudan savanna, Northern guinea savanna, Southern guinea savanna and Derived Savanna to the extreme south.
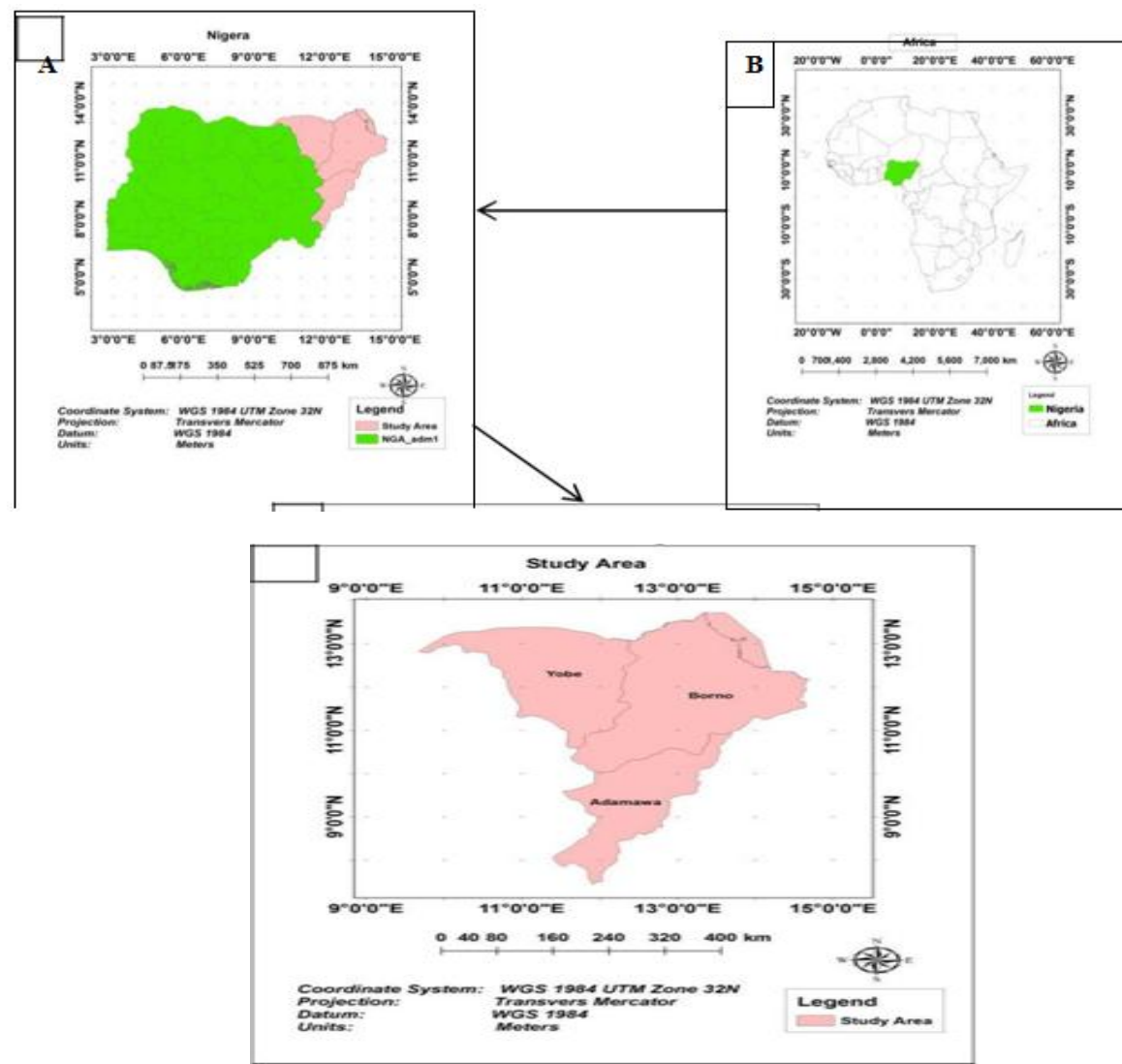

Fig.1. Administrative maps showing: (a) Location of study area in Nigeria. (b) Location of Nigeria in Africa.

(c) Study Area. 


\subsection{Data}

\section{Methodology}

Shapefiles containing road network, railway lines, waterbodies and settlements (National Space Research \& Dev. Agency [NASRDA], 2013). Shuttle Radar Topography Mission [SRTM]'s elevation image at 90m (USGS, 2014). NigeriaSat-X optical images (National Space Research \& Dev. Agency [NASRDA], July2013).

\subsection{Image Processing}

NigeriaSat-X scenes acquired in July, 2013 were obtained from National Space Research and Development Agency (NASRDA). The NigeriaSat-X sensor provide $22 \mathrm{~m}$ multi-spectral (R, G, NIR) imagery (eoPortal Directory, 2015). The three bands have the following spectral range:
Near Infrared (NIR):
$0.76-0.9 \mu \mathrm{m}$
Red (R):
$0.63-0.69 \mu \mathrm{m}$
Green $(\mathrm{G})$ :
$0.52-0.62 \mu \mathrm{m}$

Since the spatial extent of the NigeriaSat-X images is smaller than the study area extent, the images obtained were mosaicked and the study area extent was carved from the resultant mosaic (fig. 5). The image was geometrically and radiometrically corrected to avoid distortion by projecting it to UTM Zone $32 \mathrm{~N}$ and WGS-84.

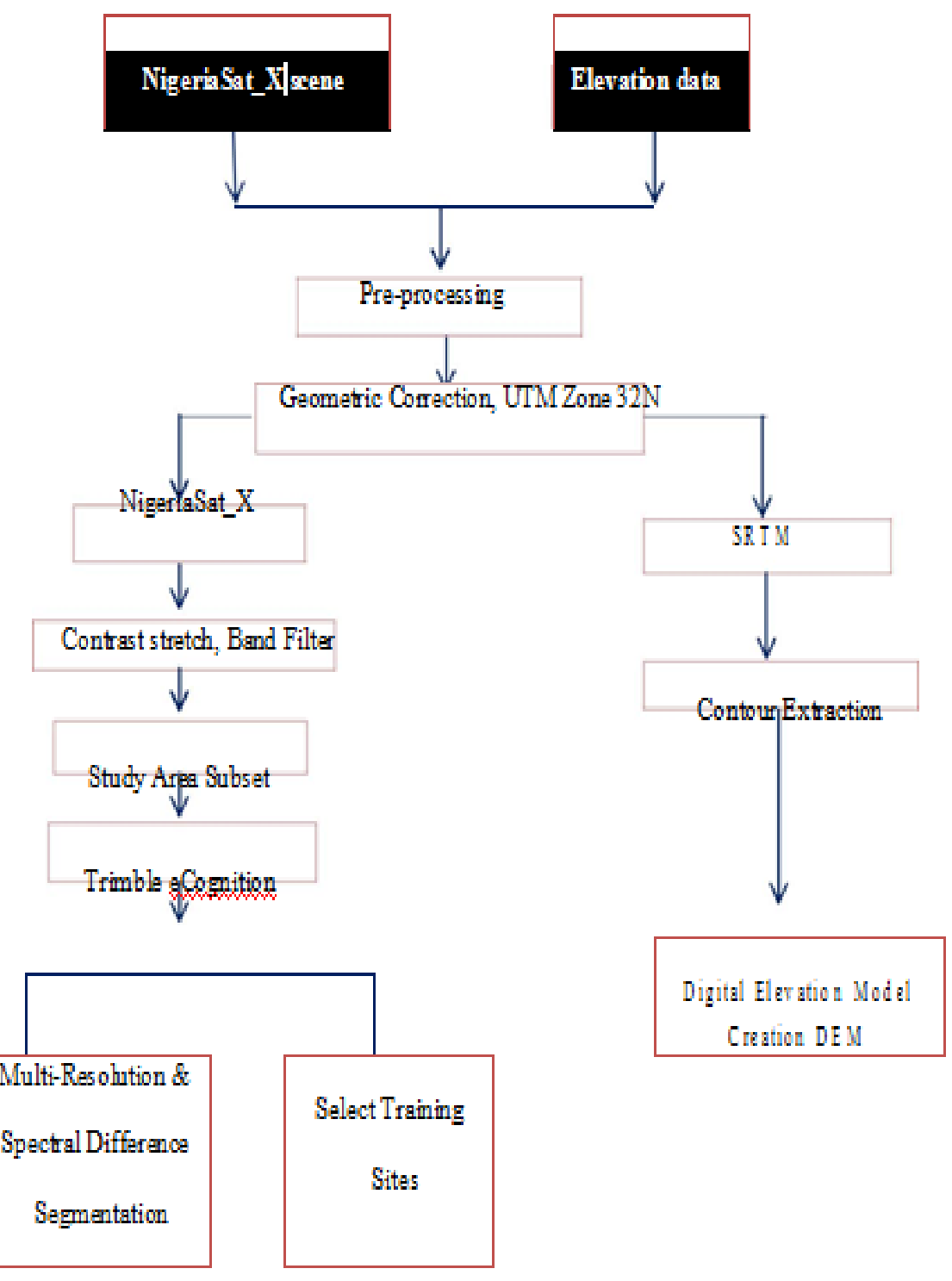




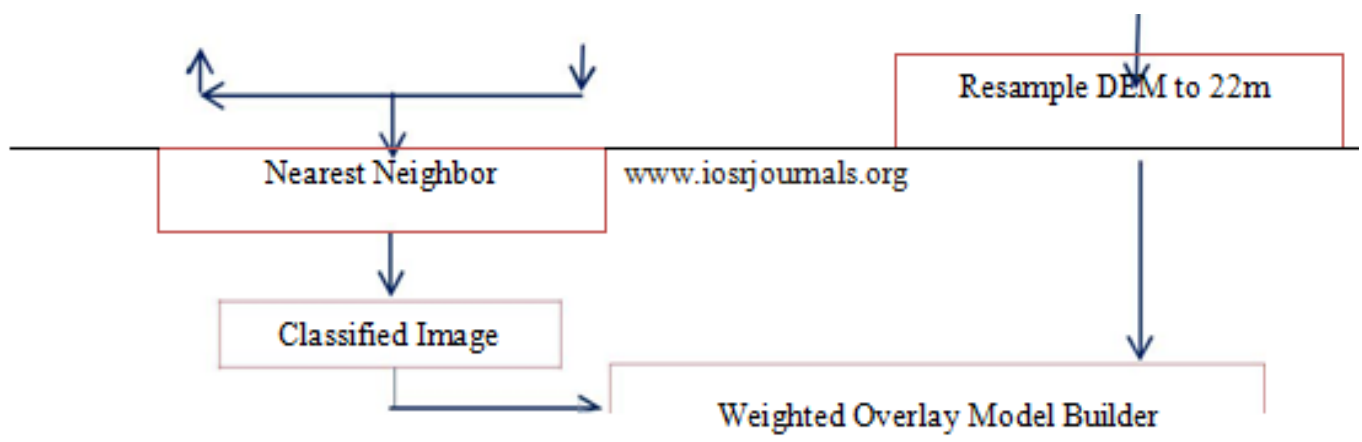

Fig. 2: Flow Chart

Object-oriented classification was applied to the carved NigeriaSat-X scenes (i.e. Fig 3a) while (Fig $3 b$ and 3c) are the result of a multiresolution segmentation of the NigeriaSat_X scenes where pixels or existing image objects were merged based on their homogeneity (i.e. colour, shape, compactness etc.). This segmentation process has an advantage of reducing heterogeneity between objects (eCognition Developer User Guide, 2014).
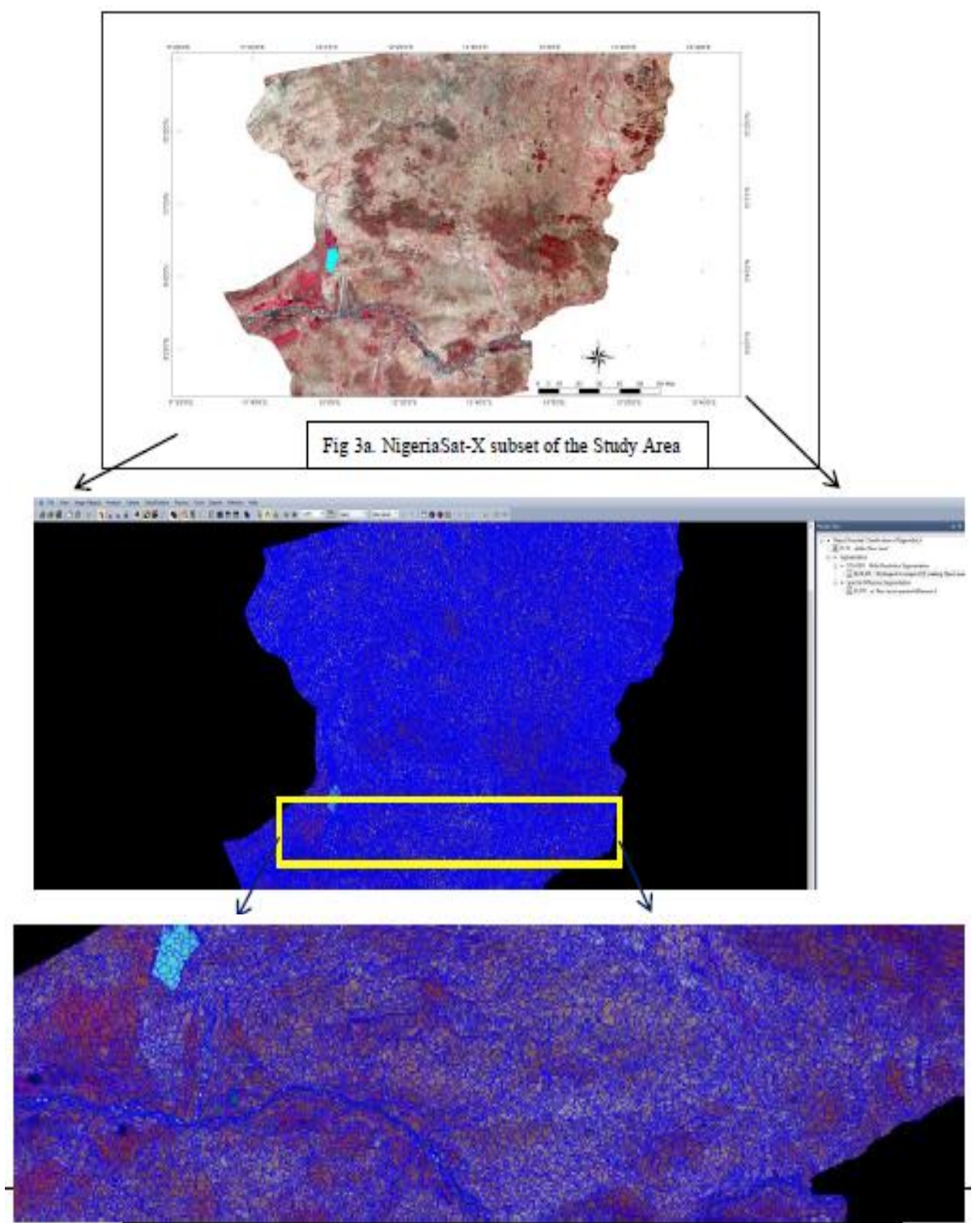

Fig $3 \mathrm{~b}$ and $3 \mathrm{c}$ shows Multiresolution Segmentation of a part of the Study area 
Fig $3 \mathrm{~b}$ and 3c shows Multiresolution Segmentation of a part of the Study area Fig. 4 is a result of spectral difference segmentation obtained by merging spectrally similar image objects produced by the previous segmentation (i.e. Fig. 3b). Here the objects are larger, more homogeneous and more discernible. Thus, rule-set for the segmentation was applied to all the images covering the study area.

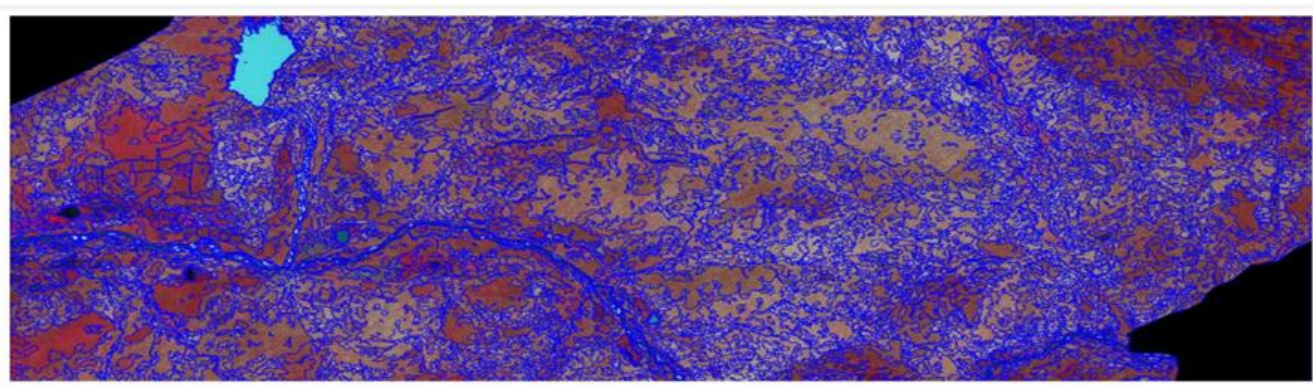

Fig 4: Spectral Difference Segmentation

Then Samples for eleven (11) classes namely: Sparse, Dense, Moderately dense vegetation, Built-up Area, Bare surface, Rock-outcrop, Wetlands, Riperian vegetation, Waterbodies, Cultivated lands and Forestreserves were identified from the segmented image and used as a training site for classification. The result of the classification (Fig. 7a) was exported to ArcMap and re-classed into five (5) classes according to their ability to provide concealment and/or cover during the dry and wet season; the tables 1 and 2 below shows the different classes that were merged.

\begin{tabular}{|c|c|c|}
\hline Classes & Merged Classes & Concealment \\
\hline & & Ability \\
\hline \multirow[t]{3}{*}{1} & Baresurface + Waterbodies (depth $>=4 \mathrm{ft}$ and & Very Low \\
\hline & width $=150 \mathrm{~m})+$ & very Low \\
\hline & Wetlands & \\
\hline \multirow[b]{2}{*}{2} & & \\
\hline & Riparian + Sparse Vegetation + Cultivated(wet season) & Low \\
\hline 3 & Moderately dense vegetation + & Medium \\
\hline 4 & Rock-outcrop + Forest Reserves & High \\
\hline 5 & Dense vegetation + Built-up areas & Very High \\
\hline \multicolumn{2}{|c|}{ Table 1: Terrain Concealment Ability during the Dry Season } & \\
\hline \multirow{2}{*}{ Classes } & Merged Classes & Concealment \\
\hline & & Ability \\
\hline & & \\
\hline
\end{tabular}

\begin{tabular}{||c|l|l|l|}
\hline $\mathbf{1}$ & Baresurface & Very Low Cover & \\
\hline $\mathbf{2}$ & Waterbodies & & \\
\hline & & Low cover & \\
\hline $\mathbf{3}$ & Sparse vegetation & Medium cover & \\
\hline $\mathbf{4}$ & $\begin{array}{l}\text { wetlands + Cultivated land + } \\
\text { Rock-outcrop + Moderately } \\
\text { Dense }\end{array}$ & High & \\
\hline & $\begin{array}{l}\text { vegetation + Riperian } \\
\text { Vegetation }\end{array}$ & & \\
\hline $\mathbf{5}$ & $\begin{array}{l}\text { Built-up + Dense vegetation + } \\
\text { Forest-Reserves }\end{array}$ & Very High & \\
\hline & & & \\
\hline
\end{tabular}

Table 2: Terrain Concealment Ability during the Rainy Season 
Shuttle Radar Terrain Mission (SRTM) 90m has a resolution of 90m at 3-arc seconds covering the study area was obtained from United State Geological Survey (USGS). Contours were extracted from the image and converted to digital elevation model (DEM). It was projected to UTM Zone 32N and WGS-84 then resampled to $22 \mathrm{~m}$ and re-classed into five (5) classes according to the local relief and ability to provide concealment and/or cover as indicated in table 3.
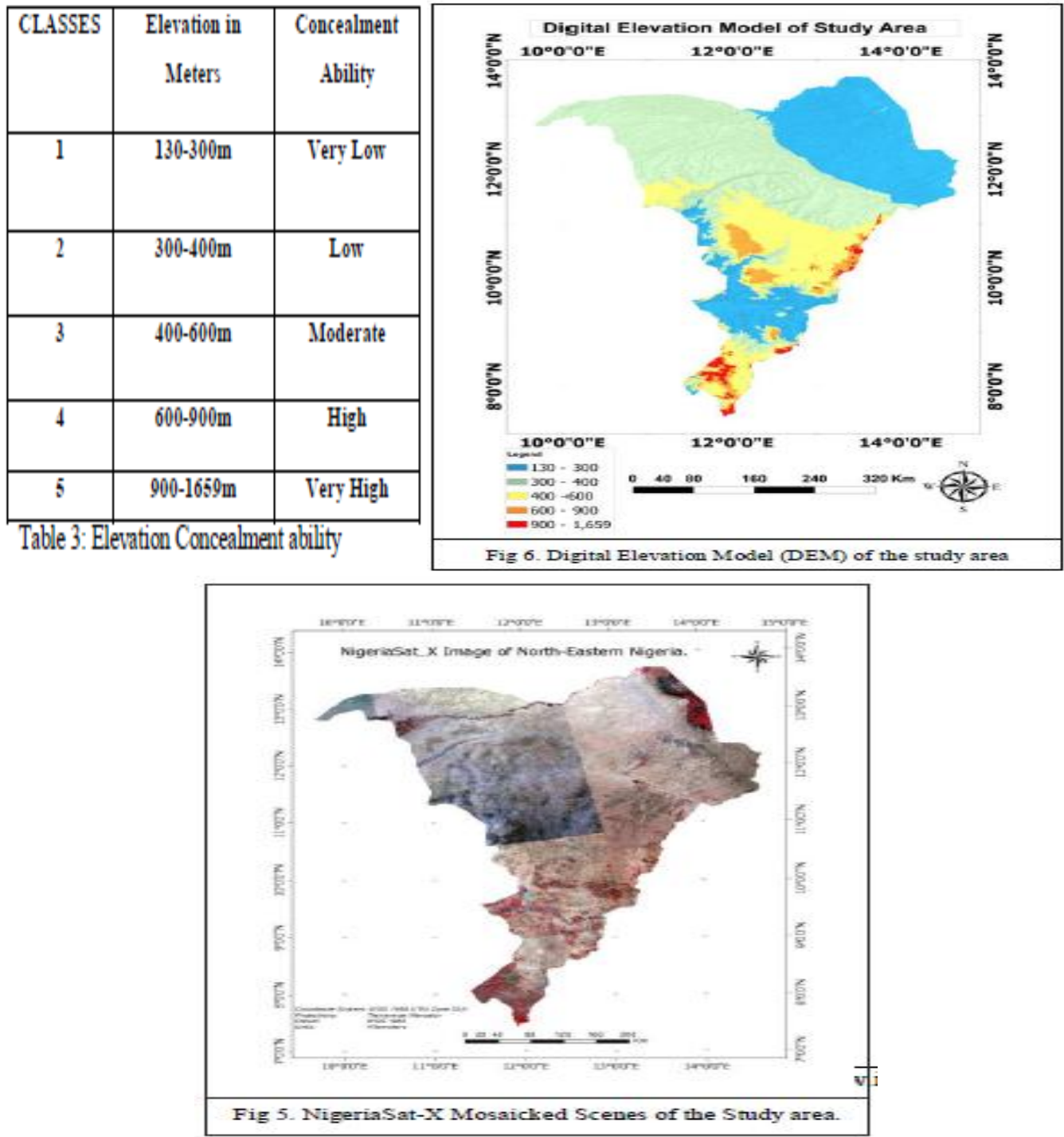

\section{Result and Discussion}

Hence, the result of the satellite image classification (Fig 7a) showed that $24.32 \%$ of the study area is cultivated which occurs mostly during the wet season while irrigation is practiced in dry season, Sparse vegetation covers $28.27 \%$, Baresurface covers $5.613 \%$, Riperian vegetation covers $2.791 \%$, Moderate dense Vegetation covers $17.54 \%$, Wetlands occupies $4.66 \%$, Waterbodies covers $6.85 \%$, Dense vegetation covers $7.88 \%$, Built-up area covers $1.076 \%$, Rock-outcrop covers $0.125 \%$ and Forest reserve covers $0.743 \%$ as indicated in the pie chart (Fig 8). The fact that large portion of the Sahel region is under agricultural practices corroborate the fact that $80 \%$ of Northerners are engaged in agriculture for their sustenance (Schaefa, 1998) which may explains why destroying farmland during war/crisis will increase the number of joblessness which will in turn add to the number of young men being recruited into insurgency. Although not environmentally friendly, cutting down forest to make way for farmlands reduces hiding places for insurgent and concealment for friendly forces. 

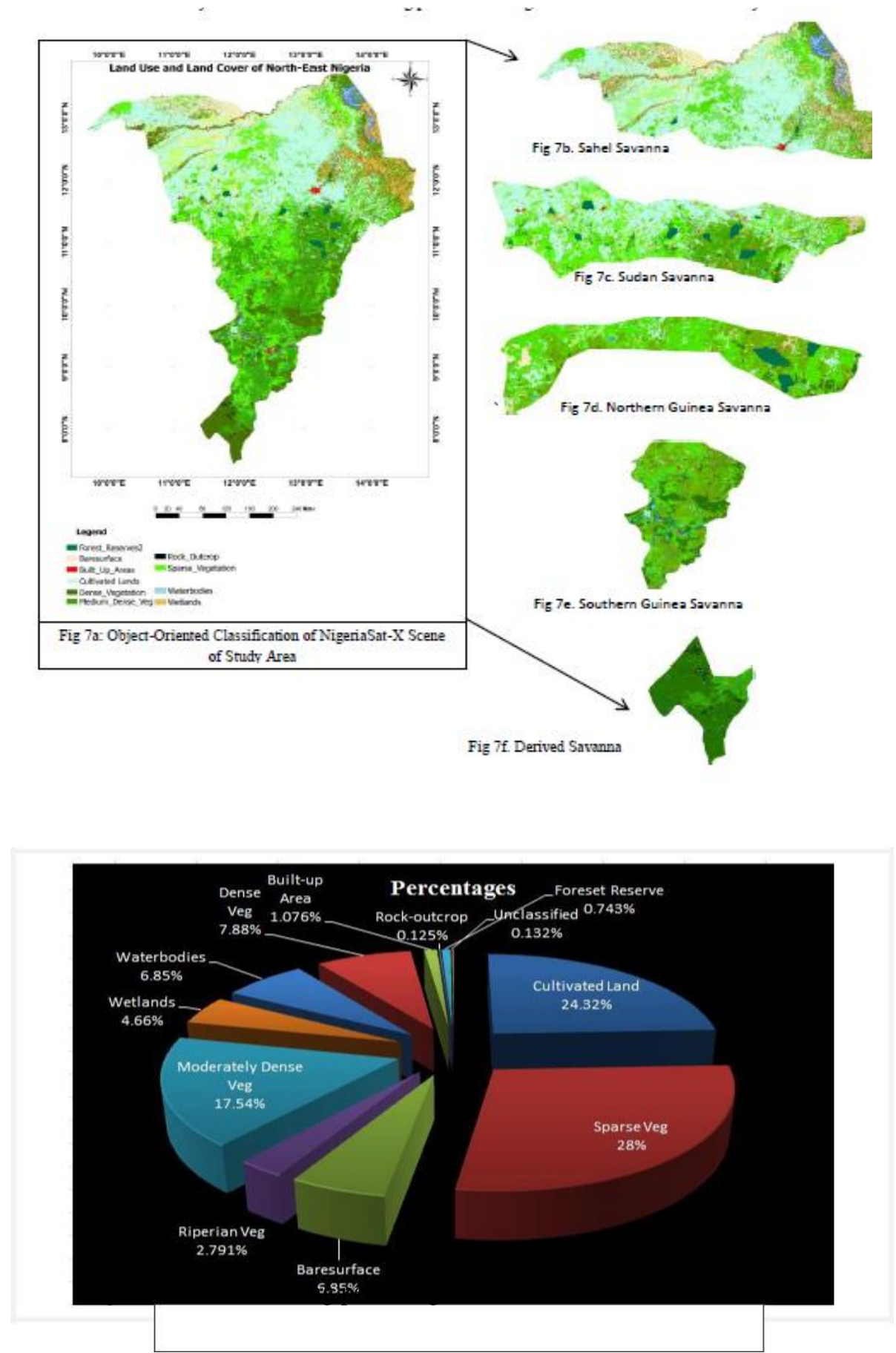

\subsection{Ecological Zones of the Study Area.}

\subsubsection{Sahel Savanna}

The Sahel Savanna (Fig 7b) is characterized by sandy soils; very sparse vegetation covering as the grass grows in individual tufts leaving bare-surfaces in-between (Sobulo, $1988 \&$ onlinenigeria, 2015). The common tree type found here is the acacia which is thorny, narrow-leafed, fairly short, and sometimes umbrella shaped

The grasses in the Sahel are short and tussocky between $0.5 \mathrm{~m}$ to $1.0 \mathrm{~m}$ high, interspersed with sand dunes (onlinenigeria, 2015). Example of dominant grasses found in the Sahel are Grootfontein bristlegrass and Schoenefeldia gracilis, the former grows to a maximum height of $150 \mathrm{~cm}$ while the latter grows to a maximum height of $90 \mathrm{~cm}$ (Clayton et al., 2006 \& Onifade and Agishi, 1988). While the scattered shrub also found here are African myrrh (grows to about 9feet which is tall enough to provide concealment for the Boko-haram fighters) and Leptadenia spartum (Iloeje, 2001). 
Grasses in the Sahel savanna are too scarce to provide any concealment from ground observation (FM $5-33,1990)$. This is due to the scanty rainfall lasting for $3-4$ months with $200 \mathrm{~mm}-600 \mathrm{~mm}$ per year; soils usually have low productivity due to inadequate moisture retention capacity and low organic matter (Adebgola, 1979).

The Sahel region is also characterized by harmattan dust from October to February and hot dry duststorms and desiccating winds occurring from December to June (Rayar, 1996; Middleton, 1985; Bankole et. al, 1994 \& CBDA, 1986); which might have an effect on vision and line of sight unless goggles and night vision are used.

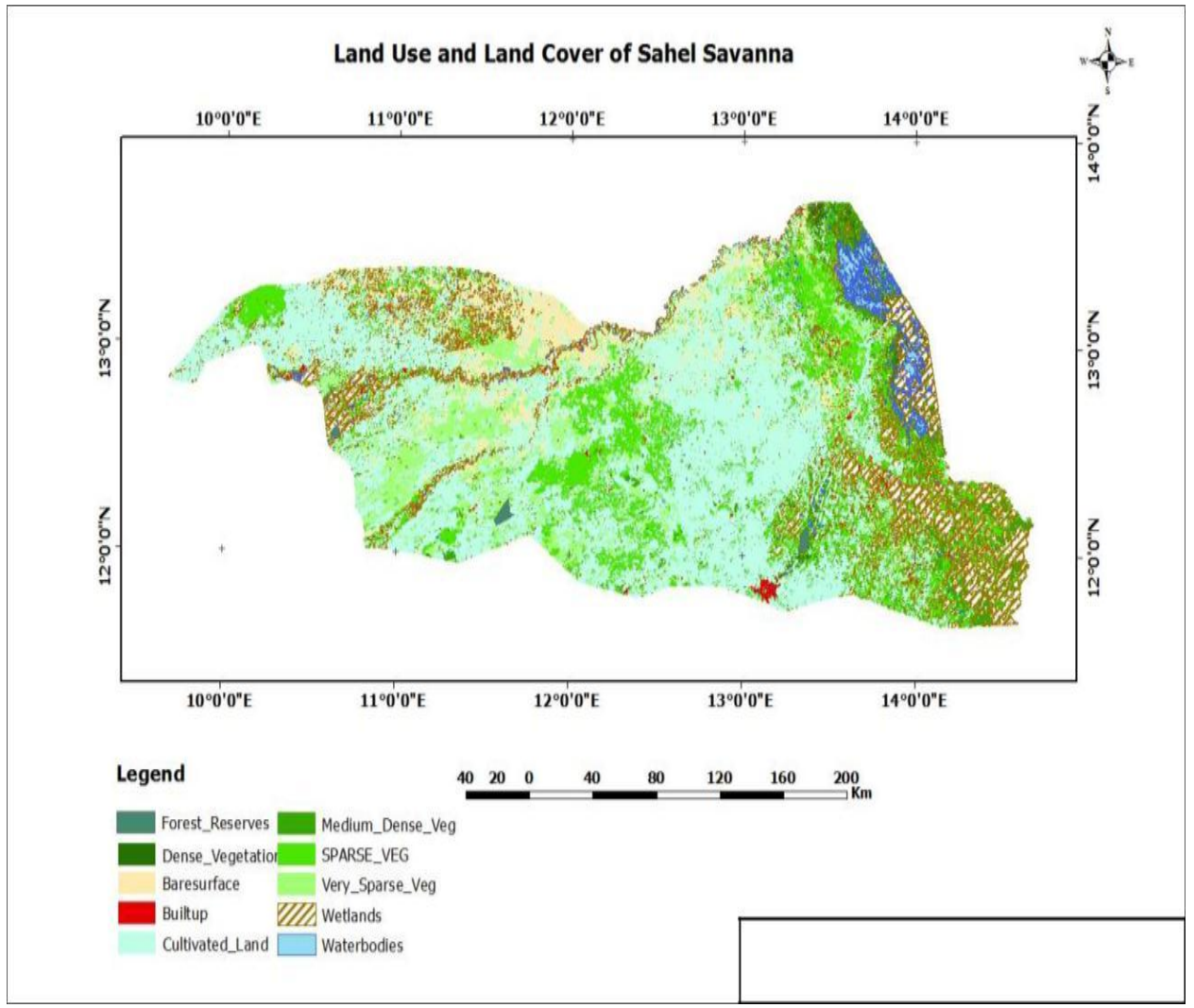

Fig 7b: LULC of Sahel Savanna

\subsubsection{Sudan Savanna}

The Sudan Savanna zone has a continuous grass cover of the short and feathery grasses on a large scale. The grass vegetation is interspersed with farms and thick bush trees such as shea butter tree, mango, Acacia, Combretum, locust bean tree and tamarind tree. However, Sudan Savanna grasses are not generally as tall, coarse or thick on the ground as those found in the Guinea savanna zone.

Dominant trees such as acacia are thorny, narrow-leafed, fairly short and sometimes umbrella-shaped. Fig 7c showed some locations of forest reserves found in the Sudan savanna which can be used for concealment in the field, especially during the rainy season when the canopy is thick; however, it is not advisable for the forest reserve to be flanking or behind the friendly forces especially if enemies can hide inside. The classification showed that $24.3 \%$ of the study area is covered by cultivated lands which is mostly practiced during the rainy season in the Sudan and Sahel savanna (with the exception of wetlands such as the YobeKomadugu, the Chad Basin and some other places practising irrigation agriculture where wheat, rice etc. are cultivated (Yahi et al., 2014)). Therefore, locations of concealment are abundant during the rainy season however, during the dry season (i.e. from October to April); the cultivated areas are mostly bare of vegetation which results in very low concealment ability as indicated by (Fig 9b) (Ogunkoya \& Dami, 2008 \& Yahi et al., 2014) except by using the built-up areas. Baresurface in Sahel Savanna (semi desert) and northern part of the Sudan Savanna can provide little or no cover, thus, providing visibility extending to several kilometres except where there are sand dunes (Fig. 9a and 9b) which can provide concealment for both friendly and foes forces (FM90-3, 1993). 


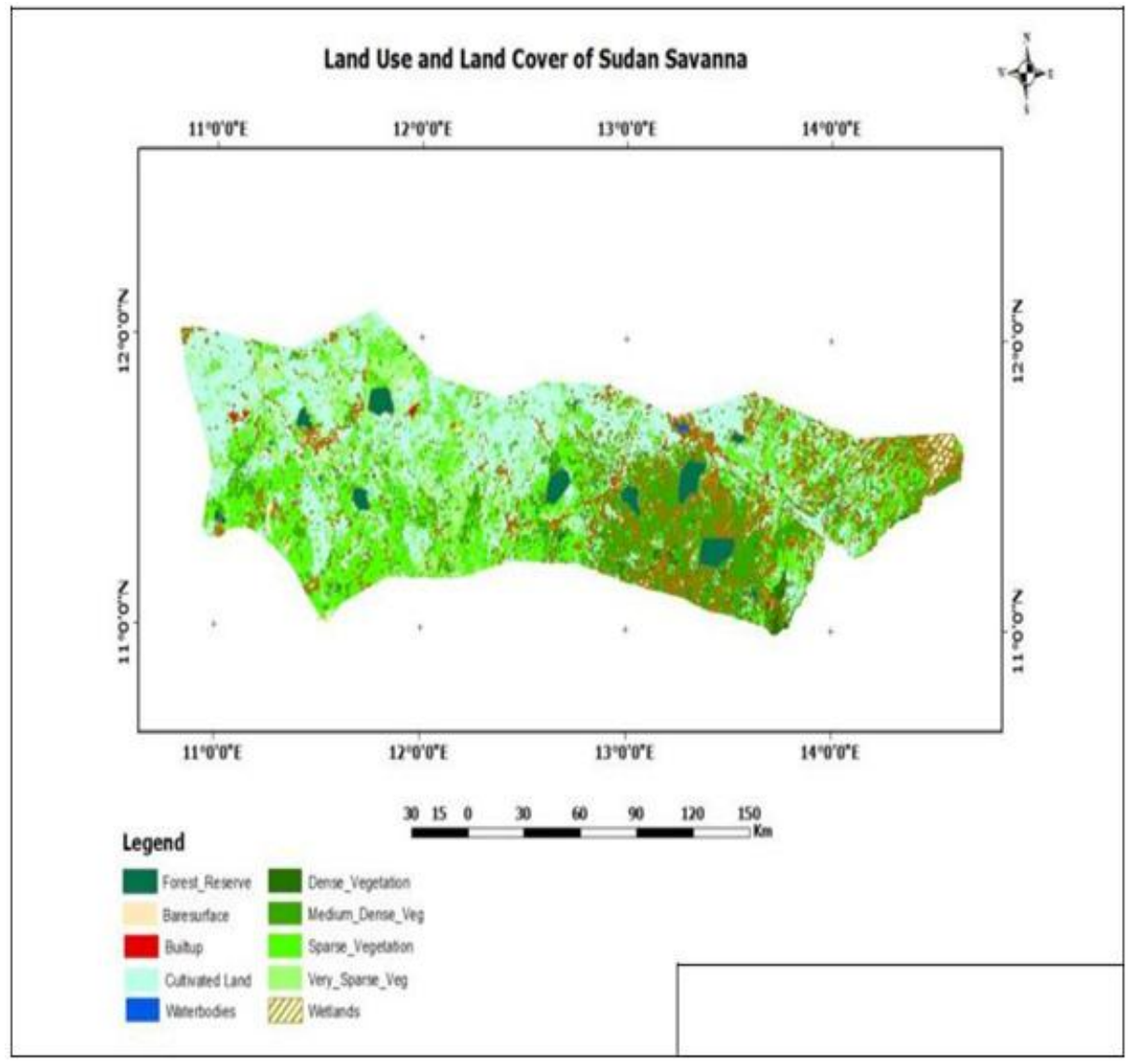

Fig. 7c: LULC of Sudan

Nonetheless, visibility can be hindered by sand-storms which can sometimes cause total darkness, this condition can be used for deception depending on which direction the storm is blowing provided there is an access to night vision or goggles. These extreme sand-storms are more prevalent in Maiduguri and other parts of the Sahel and Sudan ecological zones; especially few weeks before the rains begin, i.e around January -June (Gadzama, 1995; Rayar, 1996 and Yahi et al., 2014).

Some of the highlands found in the study area (Fig 10) consist of the Mandara Mountains (1200 $1500 \mathrm{~m}$ ) situated around the Cameroon border with Borno and Adamawa states, meanwhile the Biu Plateau rises between $600-900 \mathrm{~m}$ (Iloeje, 2001). Thus, the presence of those hill and ridges can be used as a means of cover, concealment and as obstacle to slow or stop the movement of forces by whoever controls it (FM 34-130, 1990 \& FM 3-97.6, 2000). Furthermore, at 1659m the Mandara Mountains are not high enough to be associated with altitude sickness but they cannot be climbed with heavy equipment (FM 3-97.6, 2000). Fig 10 is a digital elevation model depicting the study area's mountains and hills.

In contrast, Lake Chad basin is almost flat except for the presence of sand dunes which are long, narrow sand ridges that are overgrown by vegetation that made them fixed in their current locations (Fig 9a and $9 \mathrm{~b}$ ). The dunes are $12-30 \mathrm{~m}$ high and $275-365 \mathrm{~m}$ wide and they vary in length between $800 \mathrm{~m}$ and $12 \mathrm{~km}$ (Iloeje, 2001) and can be used as a hideout. However, not all dunes found in the Sahel region are fixed as some of them have a habit of moving due to Aeolian winds (desert) effects which suggests that they cannot be depended on even when they appear on satellite/aerial images (FM 34-130, 1990). Nonetheless, whenever they existed they can be used for concealment during field operations for example (Fig. 9c) indicate the presence of sand dunes in the NigeriaSat-X image of the study area while hillshade (Fig. 9a) shows locations in bright colours (i.e. index 1, 2 and3) where an individual hiding in it will have an advantage (due to higher elevation) over an individual hiding or approaching from the dark region (i.e. index 4 and 5) (FM 90-3, 1993).

Lake Chad is also characterized by the presence of mash/wetlands which support rainy season farming and irrigation agriculture in dry seasons, thus providing concealment from ground observation when vegetation are at least 2 meters. Therefore, air surveillance and/or airstrike will have to be employed in order to fish -out insurgents hiding in cultivated or forest reserve areas. 


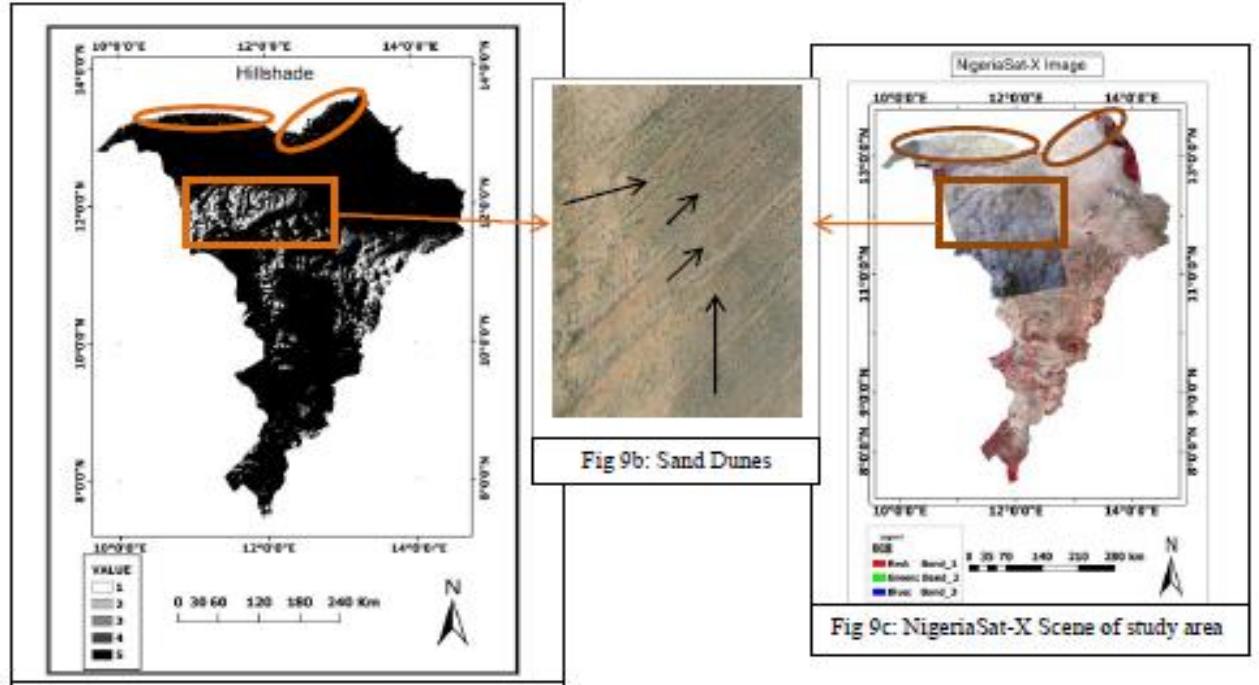

Fig 9a: Hillshade of the Study Area
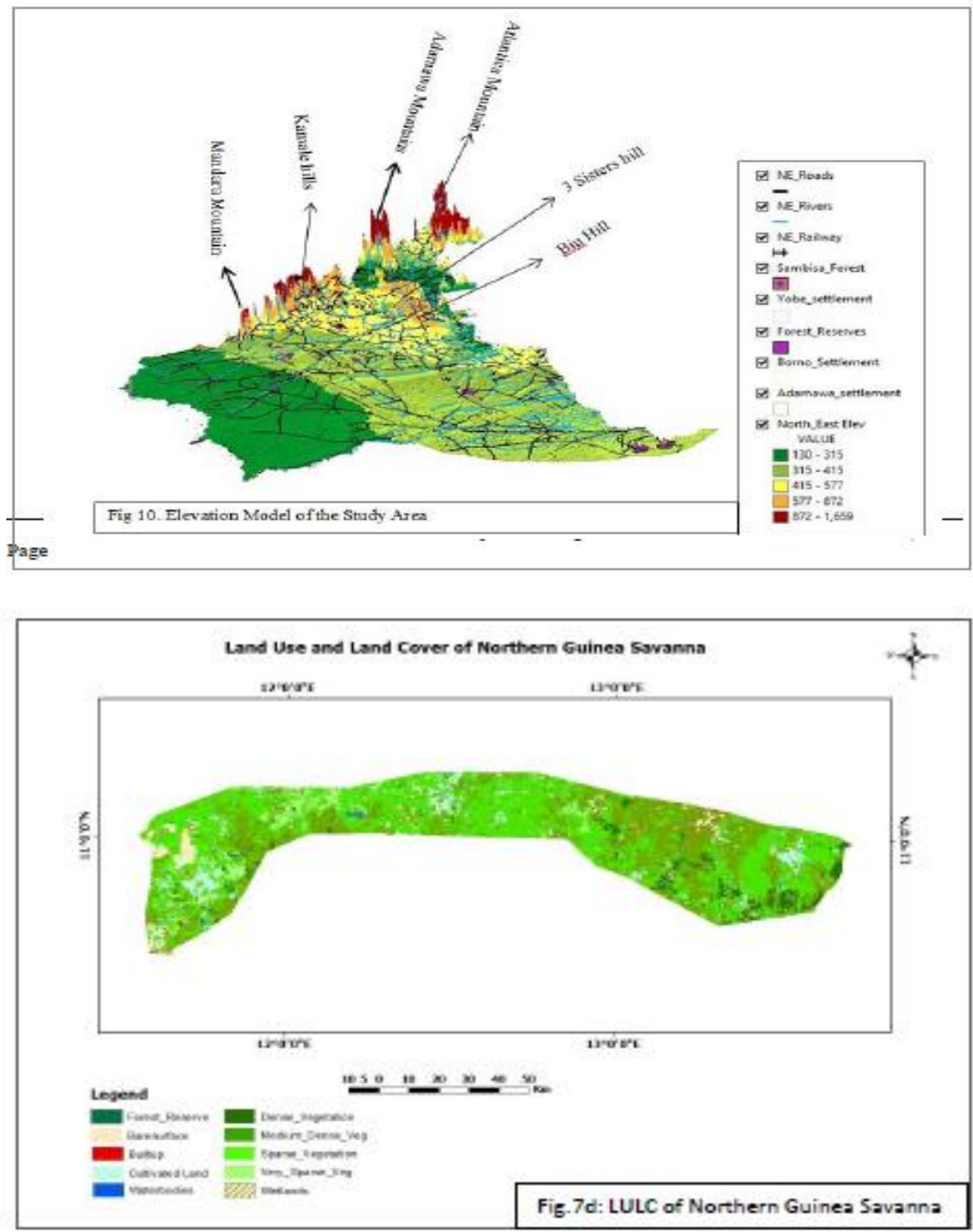


\subsubsection{Northern Guinea Savanna}

The northern guinea savanna has fewer, shorter trees (grows up to 20m), with scattered shrubs dominating the vegetation and dry season is also more intense and longer than the Southern Guinea Savanna (Pass, 2015 \& Iloeje, 2001).

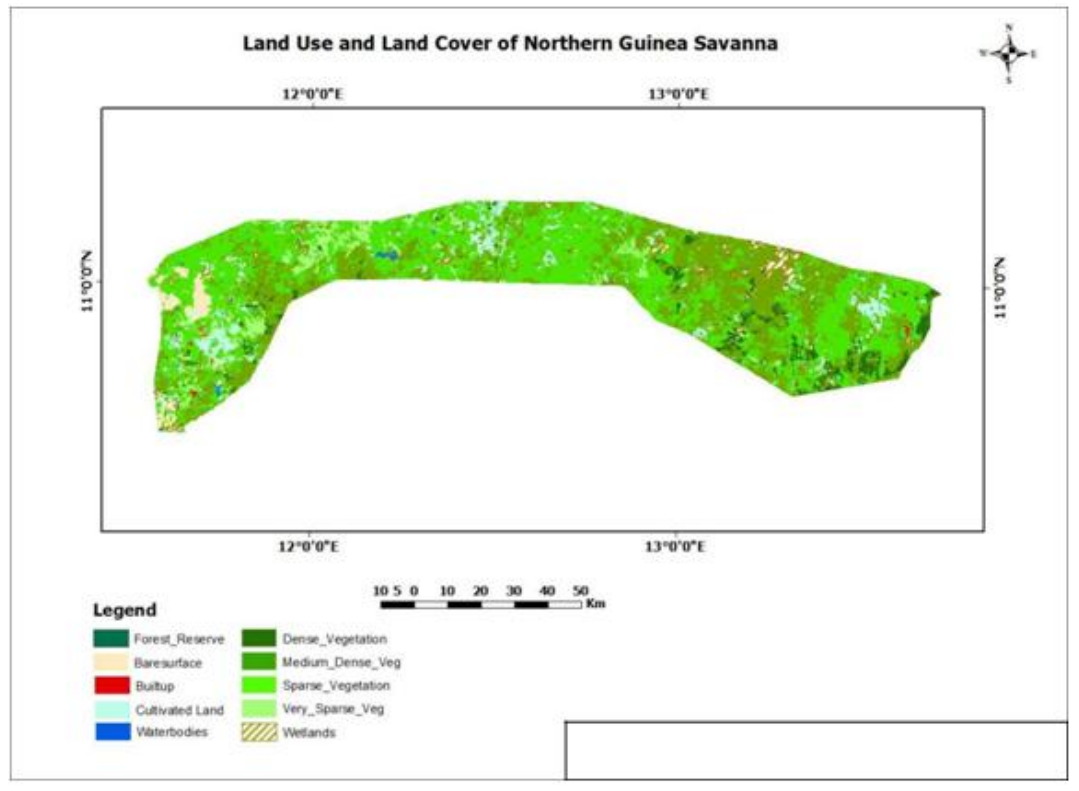

Fig.7d: LULC of Northern Guinea Savanna

4.1.4 The Southern Guinea Savanna is open savanna woodland with tall grasses up to $4 \mathrm{~m}$ (i.e. can be used as a hideout from ground observation) high with Northern gamba grass being the most predominant (Pass, 2015 and Adegbola, 1971). The Northern Gamba grass is a large perennial grass up to $4 \mathrm{~m}$ tall with tussocks up to $70 \mathrm{~cm}$ in diameter, highly flammable year round which can be used as an advantage in flushing out enemy hideout (Queensland Government, 2016). The vegetation type found here are afrzelia Africana, lophira lanceolate, danielli oliveri, vilex doniana, sedges and other weed species, cyperus sphaceolata, mariscus umbellatus, sida carpinifolia, imperata cylindrical, (keay,

1959; Clayton, 1962 \& Rains, 1963. Trees found here grow at least $25 \mathrm{~m}$ and are at least $75 \mathrm{~cm}$ wide. It is also characterized by rainfall of above $500 \mathrm{~mm}$, numerous water channels; high elevation of at least $900 \mathrm{~m}$ (Fig 10) around the Cameroon border and shorter dry season than the three zones above, it also has a prevalence of built-up areas. Therefore, its numerous vegetation cover, presence of mountains, hills, valley and build-up areas qualifies it as a target for enemy hideouts, although in other instances the hills might serve as safe-haven for the inhabitant of attacked towns located near the hills (Naij.com, 2016).

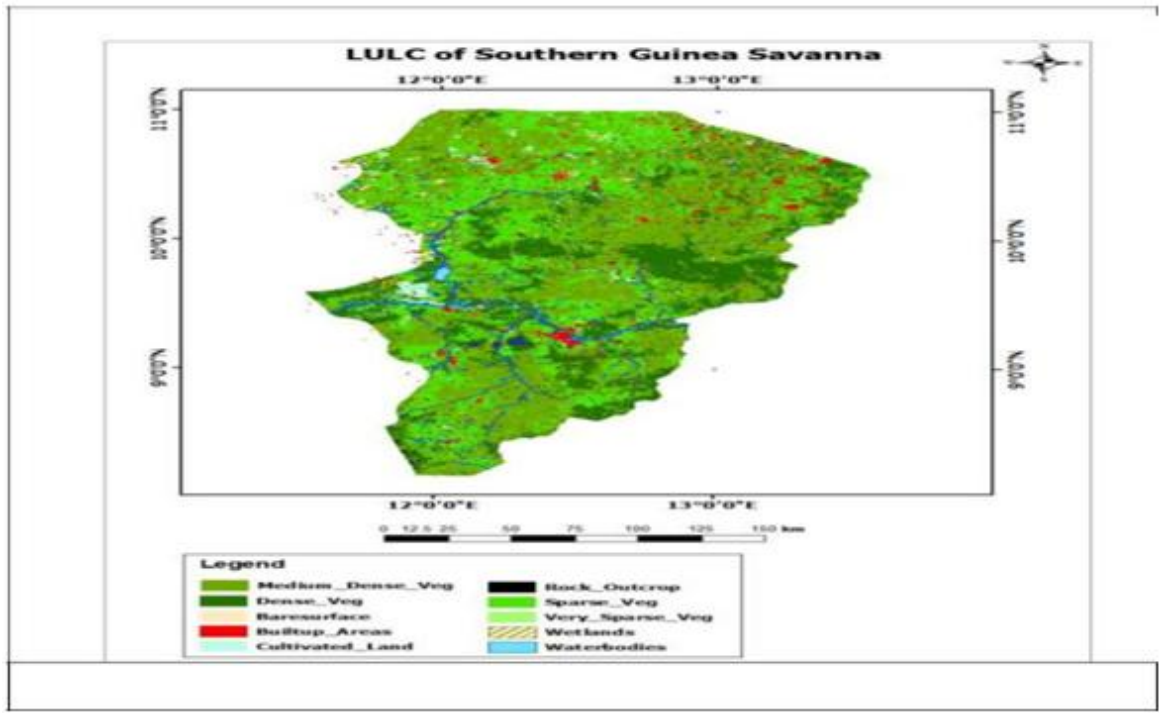

Fig.7e: LULC of Southern Guinea Savanna 


\subsubsection{Derived Savannah}

The grasslands are characterised with herbs layer that are 2 feet 6 in high forming a continuous ground cover e.g Gardenia piliostigma, Elaeis guineensis, Vitex doniana (Iloeje, 2001 and Adegbola and Olayinka, 1976). Both perennial and annual herbs are plentiful in the bare ground between the grass plants e.g H. filipendula, P. polystachyon, Dietomis fastigata. There could be numerous shrubs up to 30 feet high for instance khaya senegalensis, Daniellia oliveri. Tree species are mostly deciduous, with half of them being small leaved like the Acacia and thorny (Iloeje, 2001 and Adegbola and Olayinka, 1976). In essence, this region has more concealment ability than the previous three due to its dense vegetation cover, rock-outcrops and high elevation (atleast 1500m) around the borer with Cameroon as indicated in Fig 10.

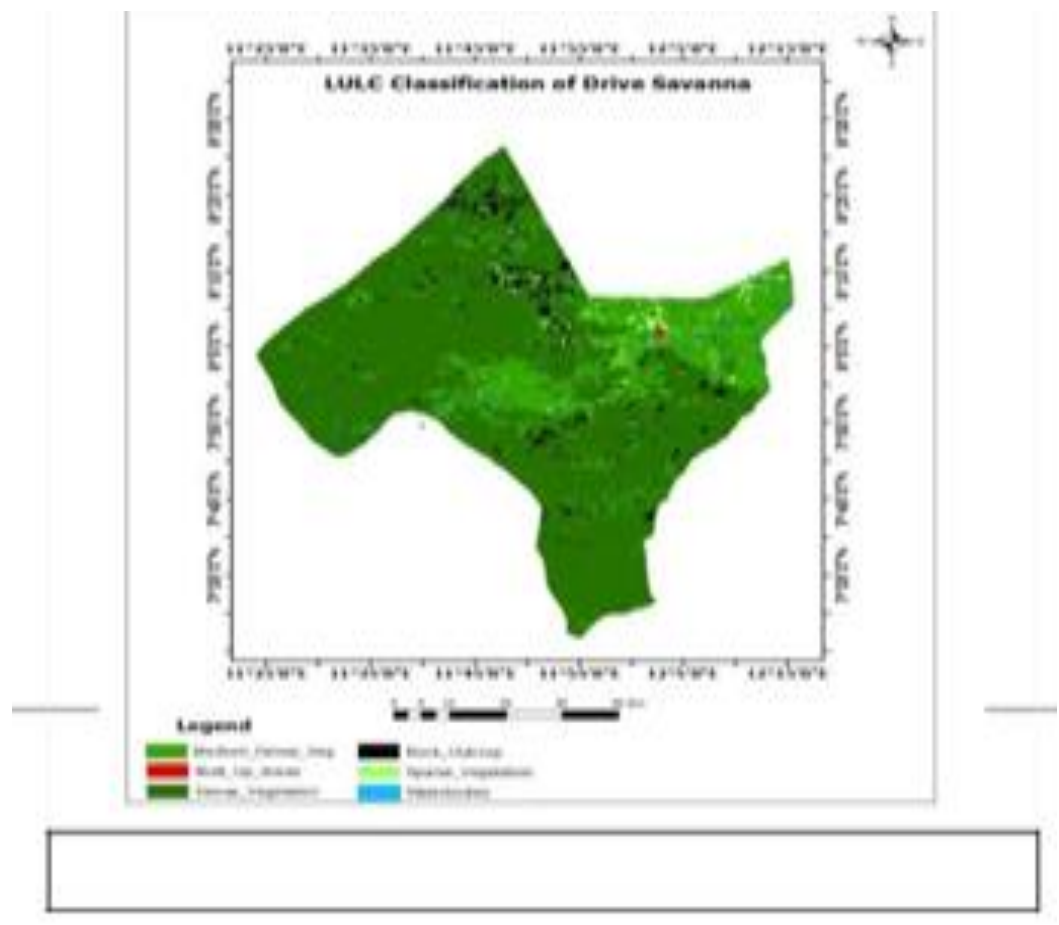

Fig 7f: LULC classification of Derived savanna

\subsubsection{Cover and Concealment Analysis}

Concealment basically means protection from observation provided by woods, underbrush, tall grasses and cultivation while cover is protection from direct and indirect enemy fire provided by rivers, craters, building, walls, caves, ditches and embankment (FM 34-130, 1990 \& OCC). From Fig 11a and 11b, locations with ability to provide cover/concealment are ranked from 1 to 5 with 1 having the lowest ability while 5 has the highest ability.

In Fig 11a the dry season has a very low vegetation cover from the northern part of the Southern Guinea savanna to the Sahel region which means the cover/concealment ability is very low putting the lives of forces at risk. Therefore, deception method will have to be employed to out-smart the enemy. Some of these deceptions include burning of grass to create smoke that hinders visibility especially when the wind speed is less than 9kmph since at this rate smoke movement is extremely slow (FM 90-3, 1993). Nonetheless, presence of built-up areas can be used for cover/concealment while industries can be used to hide heavy artillery due to their size by whoever is controlling the location. In addition, the Biu Plateau, sand dunes and the hills and mountains at the Cameron border can be used for concealment especially during the rainy season (Fig 11b) when they are overgrown by vegetation or in the evening/night when they cast shadows. 


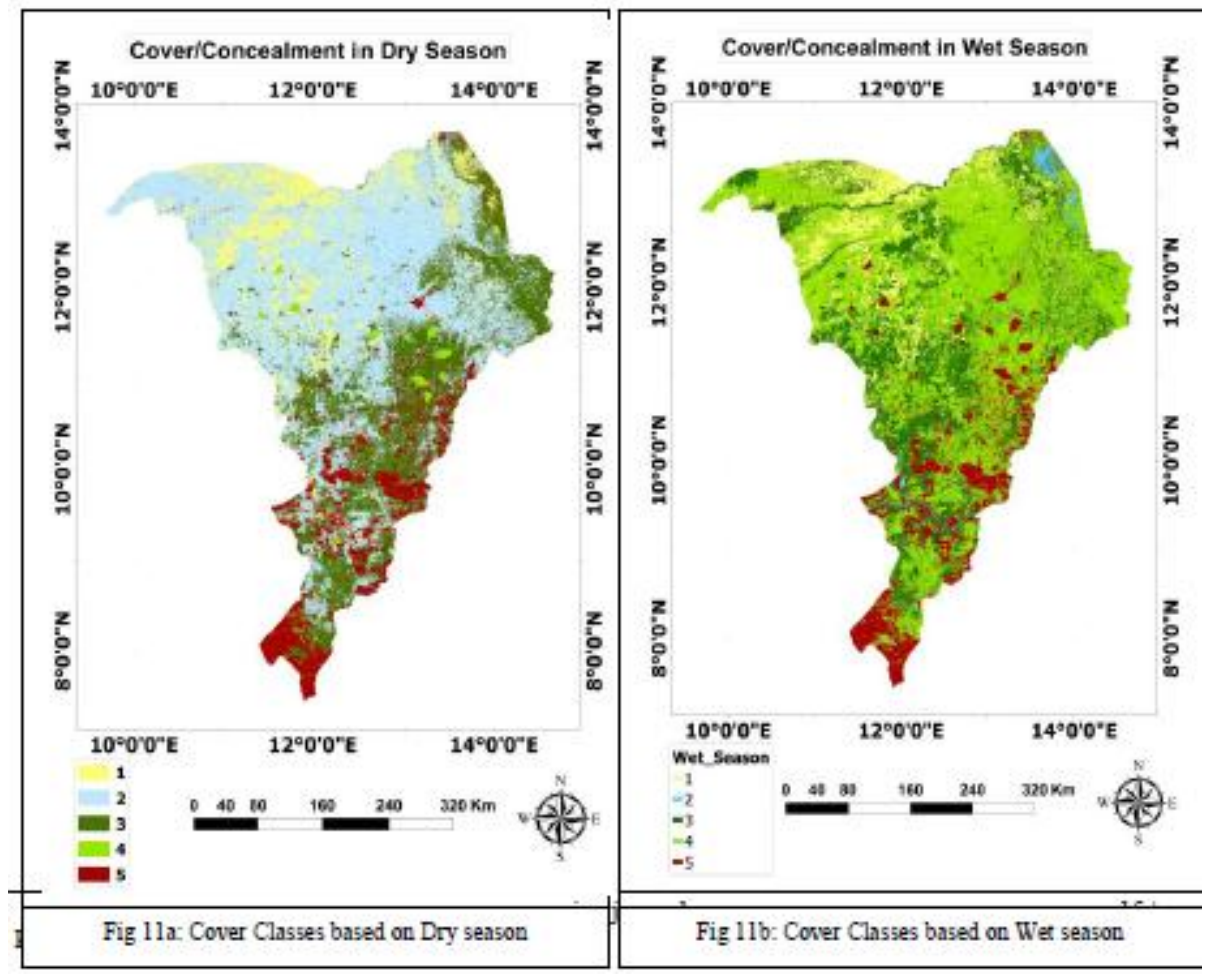

\section{Conclusion}

This research has shown the ability of spatial terrain analysis on site selection during military field operations. Geospatial terrain analysis is vital to a leader's ability to deploy, maneuver and advance his unit in the attlefield. Since a terrain is constantly changing, it is imperative for a leader to have a dedicated team of spatial analysts that can obtain remotely sensed data, process and extract useful/vital information within a short period of time. Therefore, the use of digital image capture, storing and processing cannot be over-emphasized for the guaranteed success of military field operations.

Limitation of such research in third world countries is the inability to acquire data on a regular basis to keep up with the rapid terrain change due to the rapid population growth. It should also be noted that most of the concealment and cover analysis done here are from ground observation not air.

\section{Journal Papers:}

\section{References}

[1]. M Ozaki, Y. Adachi, Y. Iwahori, and N. Ishii, Application of fuzzy theory to writer recognition of Chinese characters, International Journal of Modelling and Simulation, 18(2), 1998, 112-116.

[2]. Note that the journal title, volume number and issue number are set in italics.

\section{Books:}

[3]. R.E. Moore, Interval analysis (Englewood Cliffs, NJ: Prentice-Hall, 1966).

[4]. Note that the title of the book is in lower case letters and italicized. There is no comma following the title. Place of publication and publisher are given.

\section{Chapters in Books:}

[5]. P.O. Bishop, Neurophysiology of binocular vision, in J.Houseman (Ed.), Handbook of physiology, 4 (New York: Springer-Verlag, 1970) 342-366.

[6]. Note that the place of publication, publisher, and year of publication are enclosed in brackets. Editor of book is listed before book title.

\section{Theses:}

[7]. D.S. Chan, Theory and implementation of multidimensional discrete systems for signal processing, doctoral diss., Massachusetts Institute of Technology, Cambridge, MA, 1978

[8]. Note that thesis title is set in italics and the university that granted the degree is listed along with location information

\section{Proceedings Papers:}

[9]. W.J. Book, Modelling design and control of flexible manipulator arms: A tutorial review, Proc. 29th IEEE Conf. on Decision and Control, San Francisco, CA, 1990, 500-506 